\title{
Reviewers in this Issue
}

Prof. Md. Khalilur Rahman

Department of Surgery

Enam Medical College, Savar, Dhaka

Prof. Liaquat Ali

Department of Biochemistry \& Cell Biology

Bangladesh Institute of Health Sciences

Dhaka

Prof. Iftikhar Ahmed

Department of Microbiology

Enam Medical College, Savar, Dhaka

Prof. Khadija Nazneen

Department of Gynaecology \& Obstetrics

Enam Medical College, Savar, Dhaka

Prof. Md. Aminul Haque Khan

Department of Biochemistry

Enam Medical College, Savar, Dhaka

Dr. Md. Rezwanur Rahman

Associate Professor

Department of Biochemistry

Delta Medical College, Dhaka 